Case Report

\title{
Dental sinus with parotid duct fistula: An unusual presentation
}

\author{
Naren Shetty, Ashok Pandey, Nitin Mokal \\ Department of Plastic Surgery, Grant Medical College, GT Hospital, Mumbai, India
}

Address for correspondence: Dr. Naren Shetty, Ward 4, $1^{\text {st }}$ Floor, GT Hospital, LT Marg, Dhobitalao, Mumbai - 400001 , India. E-mail: doctornaren@yahoo.com

\section{ABSTRACT}

Injury to the parotid duct is commonly missed which may lead to a fistula subsequently. An external duct fistula is distressing to the patient because of continuous dribble of saliva during mastication. Management of established duct fistula is controversial with a variety of methods both conservative and operative being reported in the literature, each having varying degrees of success. Reconstruction of the duct is not a good option because of its modest results. Internal diversion of the opening is an innovative, simple method to correct this problem. We report the successful use of this technique in a case of distal parotid duct fistula associated with apical root abscess of maxillary molars with cutaneous sinus - an unusual presentation, with a brief review of the literature on the management of parotid fistula.

\section{KEY WORDS}

Dental sinus, internal diversion, parotid duct fistula, unusual presentation

\section{CASE REPORT}

30-year-old male presented with history of discharging sinus over the right cheek since two months [Figure 1]. Patient had undergone incision and drainage of an abscess over the right cheek under local anaesthesia two months back. Patient noticed seropurulent discharge from the operated site with soft tissue swelling on the fifth postoperative day which subsequently developed into a sinus discharging clear fluid with intermittent purulence. Demonstration of clear salivary discharge when asking the patient to chew mint confirmed our clinical suspicion of a salivary fistula. Patient also complained of loose second and third left maxillary molars two years back for which he was advised conservative treatment. The fistula did not respond to conservative management. Cannulation of the parotid duct papilla failed as it was scarred [Figure 2]. A sinogram showed a blind tract $2 \mathrm{~cm}$ long aiming towards the tooth roots [Figure 3]. The sinus was explored with a cuff of skin around the cutaneous opening. The parotid duct was identified proximally and its attachment to the tract was left intact [Figure 4]. The scarred papilla was excised. The sinus tract was also extending to the second and third molar roots [Figure 5] which were found to be loose, they were extracted. The sinus tract was internalized and the skin cuff sutured to the buccal mucosal defect thereby simultaneously dealing with the dental sinus and parotid fistula in the same setting [Figure 6]. Patient made an uneventful recovery without any recurrence of fistula [Figure 7].

\section{DISCUSSION}

The parotid duct arises from the anterior border of the parotid gland and is about $7 \mathrm{~cm}$ long. It passes over the 


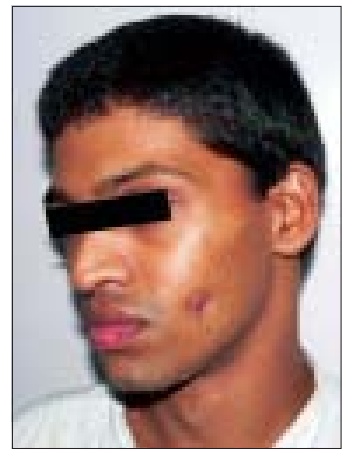

Figure 1: Preoperative photograph of dental sinus with parotid duct fistula

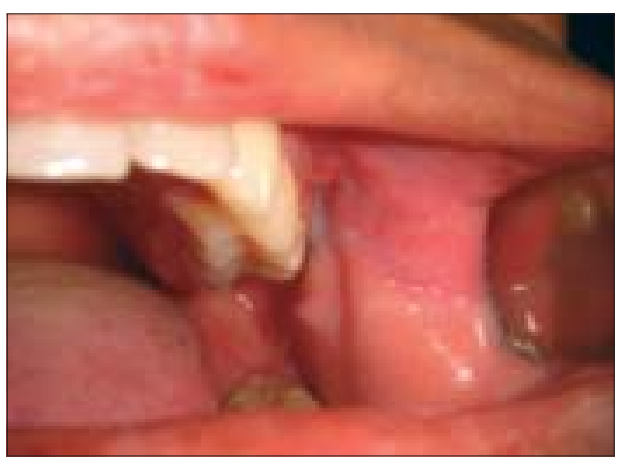

Figure 2: Intraoral photograph showing scarred papilla of parotid duct

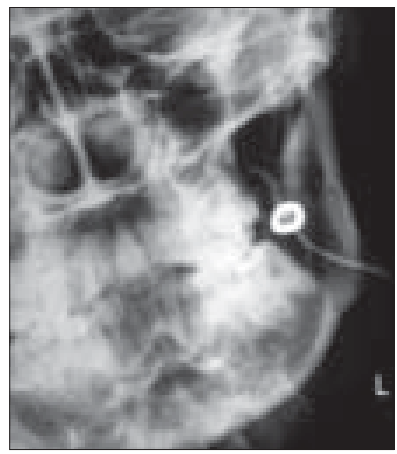

Figure 3: Sinogram showing the tract pointing towards the left maxillary molar teeth roots

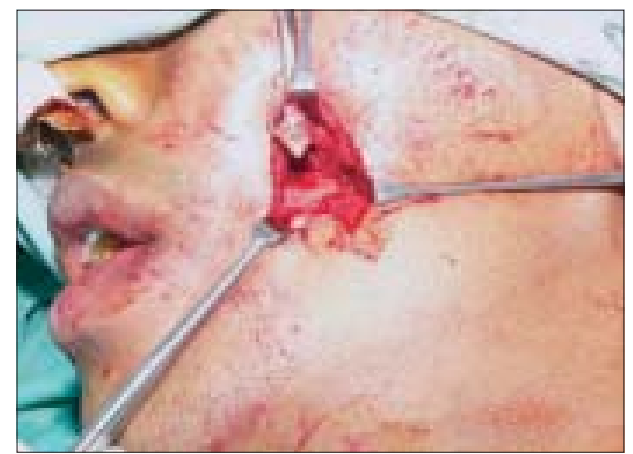

Figure 4: Intraoperative photograph showing the sinus tract with skin cuff, parotid duct and the maxillary tooth roots

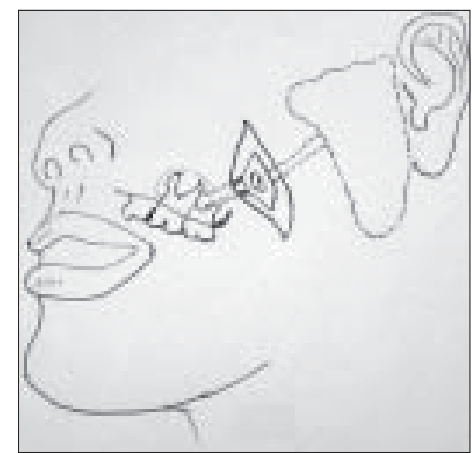

Figure 5: Line diagram showing the dental sinus tract, parotid duct and the fistulous opening with skin cuff

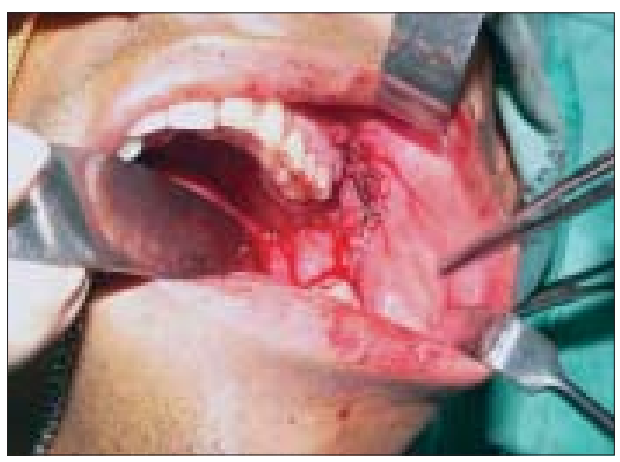

Figure 6: Internalization of the fistula with suturing of skin cuff to mucosal opening and extracted left maxillary second and third molars

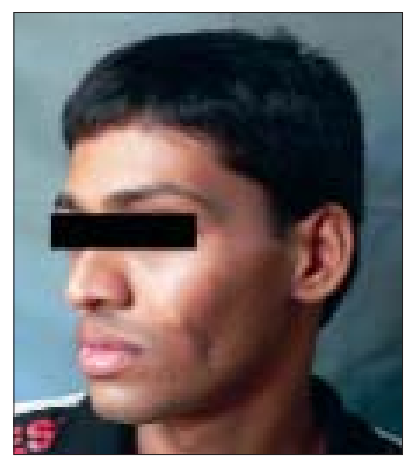

Figure 7: Post-op showing healed surgical wound without any recurrence

masseter and turns medially at its anterior border to pierce the buccinator. It travels for a varying distance beneath the buccal mucosa and opens in the papilla opposite the second maxillary molar. ${ }^{[1]}$ The course of the duct can be marked on the surface as the middle third of a straight line drawn from the anterior aspect of the tragus to the midpoint of the upper lip. ${ }^{[2]}$ The duct is accompanied by the buccal branch of the facial nerve and the transverse facial artery during its course and these structures are at risk of injury during surgery for the duct fistula. Wounds across this line should be assessed meticulously for injury to these structures. ${ }^{[2]}$ 
Nicoladoni first reported the primary anastomosis of the parotid duct following injury in 1896. Morestin reported ligation of the proximal stump in 1917. Experience in treating parotid duct injuries increased with the outbreak of World War I. ${ }^{[1]}$ Penetrating injury is the most common cause of parotid fistulas and iatrogenic injury constitutes a significant proportion of cases. ${ }^{[1,3]}$ Other causes could be malignant infiltration or parotid abscess rupture but these are uncommon. It is necessary to differentiate ductal fistulas from glandular fistulas for further management and prognostication. Sialography helps in determining this. Injury to the parotid duct if not detected primarily will result in parotid effusion usually after $24 h .^{[2]}$ This is often misdiagnosed as a soft tissue hematoma. Sialography done at this stage will detect the injury and is amenable to primary repair. If the injury is still missed it will develop into a sialocele or an external fistula.

The treatment of missed parotid injury is controversial. ${ }^{[2,4]}$ Numerous methods of treatment both conservative and operative have been described in the literature with varying success and morbidity. Conservative methods are directed towards reducing the parotid secretions. Parekh et al., have reported good results with conservative management of both glandular as well as ductal fistulas and sialocele. ${ }^{[2]}$ However, ductal fistulas took a longer time to heal than glandular fistulas and partial duct transaction healed earlier than complete transaction in their study. Anti-sialogogues can be useful adjuncts to reduce parotid secretions temporarily to facilitate closure of the fistula. ${ }^{[3,5]}$ They are unlikely to help in complete ductal transaction and can cause distressing side-effects. ${ }^{[4]}$ Radiotherapy as a means to treat parotid fistulas is not very popular because of the high dose required and the potential carcinogenic effect on the other tissues as most of these patients are in the young age group (20-30 years). ${ }^{[4,6]}$ Botulinum toxin as a means to suppress parotid secretions has been found to be very useful in the post parotidectomy fistulas but its effects in duct transactions are variable. ${ }^{[7,8]}$ Glandular fistulas have a better prognosis and respond well to conservative management whereas ductal fistulas take a long time to close. ${ }^{[4]}$

Surgical methods can be to either divert the secretions or to reduce the secretions. ${ }^{[2]}$

Tympanic neurectomy has been advocated as a method to reduce parotid secretion as secretomotor fibres for the parotid are carried by the tympanic branch of the glossopharyngeal nerve and reach the gland via the auriculo-temporal nerve. However, results are variable. ${ }^{[2,4,9]}$ Proximal duct ligation leads to glandular atrophy and closure of the fistula but carries the risk of chronic painful parotitis. ${ }^{[1,2,4,10]}$ It is advocated in failed duct reconstruction. Immediate detection and primary repair of the duct offers the best possible outcome following parotid duct injuries. ${ }^{[9,11,12]}$ The first step is identification of the proximal and distal ends. Cannulation of the papilla will identify the distal end and digital pressure on the gland will show egress of saliva in the wound from the proximal end. Meticulous repair under magnification over a stent retained for two weeks can give good long-term patency rates. ${ }^{[1]}$ Delayed reconstruction of the duct using mucosal or skin tubes gives modest results. ${ }^{[2,4]}$ Kittamura has used reversed vein graft for reconstruction of the parotid duct with variable success. ${ }^{[13]}$ Parotidectomy (superficial and total) has been described for resistant cases but is technically difficult due to the absence of definite tissue planes. It is associated with high morbidity. ${ }^{[4]}$ Diversion of parotid fistulas is less morbid and simpler than reconstructive methods. ${ }^{[14]}$ However, long-term patency of the duct and gland function needs to be evaluated. Internalization with a cutaneous cuff offers a simple solution if the fistula is in the distal part of the duct as in our case report. It is economical, less morbid than other surgeries and has no postoperative morbidity.

Immediate detection of parotid duct injury and primary repair offers the best possible outcome. The very fact that a variety of methods both conservative and operative have been reported in the literature, points to the absence of a reliable method to treat this distressing problem to the patient. Internalization of fistula with a cutaneous cuff is an innovative, practical, simple, economical and less time-consuming method with a low morbidity.

\section{REFERENCES}

1. Revis DR Jr. Consulting Staff, Department of Surgery, Division of Plastic and Reconstructive Surgery, University of Florida College of Medicine. E- Medicine article.

2. Parekh D, Glezerson G, Stewart M, Esser J, Lawson HH. Post traumatic parotid fistulas and sialocoeles: A prospective study of conservative management in 51 cases. Ann Surg 1989;209:105-11.

3. Marchese-Ragona R, De Filippis C, Marioni G, Staffieri A. Treatment of complications of parotid gland surgery. Acta Otorhinolaryngol Ital 2005;25:174-8.

4. Ananthakrishnan N, Prakash S. Parotid fistulas: A review. $\mathrm{Br} \mathrm{J}$ Surg 1982;69:641-3. 
5. Cecil AB Jr, Martin GW Jr. Banthine as an adjunct in the treatment of salivary fistulae. Am J Surg 1956;91:421-2.

6. Sridhar PS. Radiation therapy for post parotidectomy fistula. Int J Oncol 2005;27:3.

7. Arnaud S, Batifol D, Goudot P, Yachouh J. Nonsurgical management of the parotid gland and duct fistulas using type a botulinum toxin. Plast Reconstr Surg 2006;117:2426-30.

8. von Lindern JJ, Niederhagen B, Appel T, Bergé S, Reich RH. New prospects in the treatment of traumatic and postoperative parotid fistulas with type a botulinum toxin. Plast Reconstr Surg 2002;109:2443-5.

9. Davis WE, Holt GR, Templer JW. Parotid fistula and tympanic neurectomy. Am J Surg 1977;133:587-9.

10. Abramson M. Treatment of parotid duct injuries. Laryngoscope
1973;83:1764-8.

11. Epker BN, Burnette JL. Trauma to the parotid gland and duct: Primary treatment and management of complications. J Oral Surg 1970;28:657-70.

12. Halsband ER, Doku HC, Maloney PL. Parotid duct laceration: Report of cases. J Oral Surg 1970;28:123-4.

13. Kittamura T, Togawa K. Surgery of Stensen's duct. Arch Otolaryngol 1971;93:189-93.

14. Doctor VS, Rafii A, Enepekides DJ, Tollefson TT. Intraoral transposition of traumatic parotid duct fistula. Arch Facial Plast Surg 2007;9:44-7.

Source of Support: Nil, Conflict of Interest: None declared. 